\title{
Gladiolus italicus Miller Bitkisinin Uçucu Yağının Kimyasal Bileşimi ve Biyoaktif Özellikleri
}

\author{
Osman ÜÇÜNCÜ*, Cemalettin BALTACI, Şeyda Merve İLTER \\ Gümüşhane Üniversitesi Mühendislik ve Doğa Bilimleri Fakültesi Gıda Mühendisliği Bölümü, 29100, Gümüşhane
}

Geliş tarihi/Received 16.06 .2016

Düzeltilerek geliş tarihi/Received in revised form 15.07.2016

Kabul tarihi/Accepted 18.07.2016

$\ddot{O} z$

Gladiolus italicus Miller (Iridaceae) bitkisinin uçucu yă̆ GC-FID/MS teknikleriyle analiz edilmiştir. G. italicus uçucu yă̆ında \%88.75'lik kısmı oluşturan toplam 34 bileşiğin yapısı aydınlatılmıştır. Palmitik asit (\%35.84) ve etil linoleat (\%11.62) G. italicus'un uçucu yağının ana bileşenleridir. Bitkiden elde edilen uçucu yağın antimikrobiyal aktivitesi on iki adet gram negatif ve gram pozitif patojen bakteri ve beş mantara karşı araştırılmıştır Uçucu yağın orta derecede

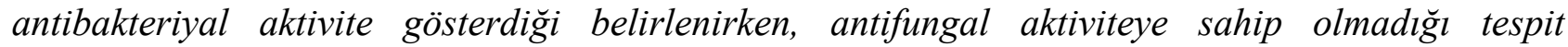
edilmiştir. Ayrıca G. italicus'un toplam fenolik miktarı 437.3 GGA/L olarak belirlenmiştir.

Anahtar kelimeler: Biyoaktivite, GC-MS/FID, Gladiolus italicus Miller, Uçucu Yă̆

\section{Chemical Composition and Bioactive Properties of the Volatile Oil of Gladiolus italicus Miller}

\begin{abstract}
The essential oil of Gladiolus italicus Miller (Iridaceae) was investigated by means of GC-FID/MS techniques. A total of 34 compounds were identified, constituting over $88.75 \%$ of the oil composition of G. italicus. Palmitic acid (35.84\%) and ethyl linoleate (11.62\%) were the major compounds in the volatile of G. italicus. The antimicrobial activity of the isolated essential oil of the plant was also investigated against to twelve $G+$ and $G$-bacterian and five fungus. It was determined that essential oil showed moderate antibacterial activity and no antifungal activity. And also, the amount of total phenolic quantified in G. italicus essential oil was found $437.3 \mathrm{GGA} / \mathrm{L}$.
\end{abstract}

Keywords: Bioactivity, GC-FID/MS, Gladiolus italicus Miller, Essential oil

\section{Giriş}

Çok yıllık soğanlı bir bitki olan ve Iridaceae ailesinin en geniş sınıflarından olan Gladiolus L. (Iridaceae)'nin 260'tan fazla türü bulunmaktadır (Goldblatt, 1996). Gladiolus türleri daha çok Sahraaltı Afrika bölgesinde bulunur ve burada 160 endemik türün bulunduğu bildirilmiştir (Manning ve
Goldblatt, 2008). Türkiye'de 11 türü bulunan Gladiolus'un 9 türü Tan ve Edmonson (1984) tarafından tanımlanmıştır ve bunlardan 4 tanesi endemik olarak bulunmaktadir. Gladiolus italicus daha çok yol kenarlarında ve taşlık alanlarda 1900 metre yüksekliğe kadar yetişmektedir. Gladiolus soğanları Afrika'nın bazı ülkelerinde halk arasında dizanteri ve belsoğukluğu tedavisinde

\footnotetext{
* Osman ÜÇÜNCÜ, osmanucuncu@yahoo.com, Tel: (456) 23310 00-1861
} 
kullanılmaktadır (Nguedia vd., 2004). Türkiye'de ise geleneksel olarak afrodizyak ve kusturucu özelliğinden dolayı halk arasında kullanılmaktadır (T. Baytop, 1999). Ayrica Gladiolus italicus ve G. atroviolaceus soğanları ise dondurma ve diğer sütlü gıdalarda kullanılmaktadır (Öztürk ve Özçelik, 1991).

Yapılan literatür araştırmaları bazı Gladiolus L. türlerinde ( $G$. atroviolaceus, $G$. gandavensis ve $G$. segetum) flavonol, antosiyanidin, antrakinon ve saponinler gibi doğal bileşiklerin olduğunu ve bu türlerin çeşitli biyolojik aktivitelerinin olduğunu göstermiştir (Hajiboland ve Manafi, 2007, Wang vd., 2003, Bazzaz vd., 1997). Ayrica G. atroviolaceus bitkisinin uçucu yağının kimyasal bileşimi ve antimikrobiyal aktivitesi çalışılmıştır (Kahriman vd., 2012). Ancak Gladiolus italicus Miller bitkisinin uçucu yağının hem kimyasal kompozisyon hem de biyolojik aktiviteleri hakkında herhangi bir çalışmaya rastlanmamıştır. $\mathrm{Bu}$ çalışmada Türkiye'de bulunan $G$. italicus bitkisinin uçucu yağının kimyasal kompozisyonu ile uçucu yağ ekstraktının antibakteriyel, antifungal ve antioksidan özellikleri araştırılmıştır.

\section{Metaryal ve Yöntem}

\subsection{Yapılan Çalışmalar}

Gladiolus italicus Miller bitkisi Gümüşhane ili Torul ilçesi Limni Gölü kenarlarından (yaklaşık $1700 \mathrm{~m}$ ) 2013 yılı ağustos ayında toplanmıştır. Bitki materyali Dr. Mutlu GÜLTEPE tarafından teşhis edilmiş ve KTUB-509 numarası verilerek depolanmıştır.

\subsubsection{Clevenger Tipi Hidrodestilasyon İslemi:}

Toplanan bitki materyalleri gölgede kurutulmuş ve $130 \mathrm{~g}$ tartılmıştır. Blender yardımıyla küçük parçalara ayrılan kurutulmuş bitki, 2 litrelik cam balona alınarak üzerine $800 \mathrm{~mL}$ saf su ilave edilmiş ve clevenger tipi su buharı destilasyon cihazında 4 saat isıtılmıştır. Oluşan buharlar $15 \mathrm{C}^{\mathrm{o}}$ de soğutulmuş ve $14.9 \mathrm{mg} \mathrm{(w/w}$
\%0.012) uçucu yă̆ elde edilmiştir. Oluşan uçucu yağ HPLC kalitesinde $1 \mathrm{~mL}$ hegzan ile kahverengi viale alınmış ve susuz $\mathrm{Na}_{2} \mathrm{SO}_{4}$ ile kurutularak analizler için $-5 \quad \mathrm{C}^{0}$ ' de saklanmıştır (Tunalıer vd., 2002).

\subsubsection{GC ve GC-MS Analizleri:}

$\mathrm{Bu}$ çalışmada yapılan GC-MS ve GC-FID analizleri literatüre göre yapılmıştır (Üçüncü vd., 2010).

\subsubsection{Bileşenlerin Tanımlanması:}

Uçucu yağın kimyasal içeriğinin belirlenmesi için her bir bileşik, öncelikle kütle spektrumları analizin yapıldığı bilgisayarın WILEY ve NIST kütüphaneleri ile, daha sonra ise alıkonma süreleri otantik örnekler (limonen, nonadekan, heneikosan ve trikosan) ve literatür verileri ile karşılaştırılarak belirlenmiştir (Adams 2004, Kahriman vd., 2010, Üçüncü vd., 2009, Skaltsa vd., 2003).

\subsubsection{Antimikrobiyal Aktivite Analizi:}

Bütün test mikroorganizmaları Gümüşhane Üniversitesi Gida Mühendisliği Laboratuarlarından temin edilmiştir. Uçucu yă ekstraktının antimikrobiyal aktiviteleri Aeromonas hydrophila ATCC 7965, Bacillus cereus ATCC 33019, Bacillus subtilis ATCC 6633, Enterobactercloacea ATCC 13047, Escherichia coli ATCC 11230, Escherichia coli O157:H7 ATCC 33150, Klebsiellapneumoniae ATCC 13883, Listeria monocytogenes ATCC 7644, Proteus vulgaris ATCC 13319, Pseudomonas aeruginosa ATCC 17853, Salmonella typhimurium ATCC 14028, Staphylococcus aureus ATCC 25923, Saccharomyces cerevisiae BC 5461, Candida albicans ATCC 1223'a karşı agar difüzyon metodu kullanılarak belirlenmiştir. Ekstraktlar 1000 ppm olacak şekilde hekzanda çözülerek stok çözeltiden hazırlanmıştır (Maksimovic vd., 2005, Sağdıç ve Özcan 2003).

Agar Difüzyon metodu:

Bütün mikroorganizmalar 18 saat $37^{\circ} \mathrm{C}$ de nutrient broth ile $C$. albicans, $\mathrm{S}$. cerevisiae, 
A.niger, A.flavus, Penicillum ise 42 saat $27^{\circ} \mathrm{C}$ 'de malt ekstrakt besiyerinde geliştirilmiştir. Steril nutrient agar ve malt ekstrakt agar $45^{\circ} \mathrm{C}$ 'ye soğutularak geliştirilen mikroorganizmalar \%1 olacak şekilde inoküle edilmiş ve petrilere dökülmüştür. Agarlar katılaşınca, agarların üzerine $5 \mathrm{~mm}$ çapında kuyucuklar açılmıştır. Ön ekstraksiyonu yapılan örnekler kuyucuklara $50 \mu \mathrm{L}$ olacak şekilde ilave edilmiştir. Kontrol amaciyla hekzan kullanılmıştır. Daha sonra petriler bakteriler için $37^{\circ} \mathrm{C} 24$ saat, küfler için ise $27^{\circ} \mathrm{C} \quad 48$ saat inkübasyona bırakılmıștır. Antimikrobiyal aktivite, test mikroorganizmalarının inhibisyon zonları ölçülerek belirlenmiștir. Zonlar milimetre olacak şekilde ölçülmüştür (Perez vd., 1990).

\subsubsection{Antioksidan Aktivite Testleri:}

Serbest Radikal süpürücü aktivitenin Belirlenmesi:

Serbest radikal süpürücü aktivite değeri DPPH metodu ile belirlenmiştir. $4 \mathrm{~mL} \quad 0.1$ $\mathrm{mM}$ olacak şekilde metanol ile hazırlanan DPPH çözeltisi $G$. italicus bitkisinin uçucu yağ ekstraktına ilave edilmiştir. Karışım 30 dakika oda sicaklığında ve karanlıkta bekletilerek 517 nm'de metanole karş1 okunmuştur. Ölçümler 5 paralel şeklinde tekrarlanmış ve ortalaması hesaplanmıştır (Sanchez-Moreno, C. vd., 1998). \% inhibisyon sonuçları aşağıda belirtilen formüle göre hesaplanmıştır;
$\%$ inhibisyon $=($ Kontrol Absorbans1-Örnek Absorbans1 / Kontrol Absorbans1) x 10

\section{Toplam Fenolik Miktarl:}

Toplam fenolik madde miktarının analizi için Sagdıç ve arkadaşlarının kullandığı FolinCiocalteu metodu kullanılmıştır. Özetle, ön ekstraksiyon yapılan ekstraktlar $40 \mu \mathrm{L}$ test tüplerine ilave edilip üzerine $2.4 \mathrm{~mL}$ saf su ilave edilir. Karışıma 200 mL Folin-Ciocalteu fenolik ayırac1, $600 \mathrm{~mL}$ sodyum karbonat çözeltisi ve $760 \mathrm{~mL}$ saf su ilave edilir. Karıșım 15 sn boyunca karıştırılır. Folin Ciocalteu ayıracının indirgenmesi alkali ortamda mavi rengin ortaya çıkması ile sonuçlanır. 2 saat inkübasyondan sonra 765 nm de absorbansı ölçülür. Tüm ölçümler beş paralel olarak yapılmış ve ortalamaları alınmıştır. Hesaplamalarda kullanılan grafik Şekil 1'de görülmektedir. Sonuçlar GAE/L olarak verilmiştir (Gámez-Meza, N. vd., 1999).

\section{Bulgular, Sonuç ve Tartışma}

$130 \mathrm{~g}$ kurutulmuş $G$. italicus bitkisine uygulanan hidrodestilasyon işlemi sonucunda $\% 0.012$ verimle $14.9 \mathrm{mg}$ uçucu yă elde edilmiştir. Uçucu yağın kimyasal yapısında GC-MS analizi sonucunda literatür verileri ile karşılaştırılarak \%88.75 oranında 34 bileşik tanımland1.

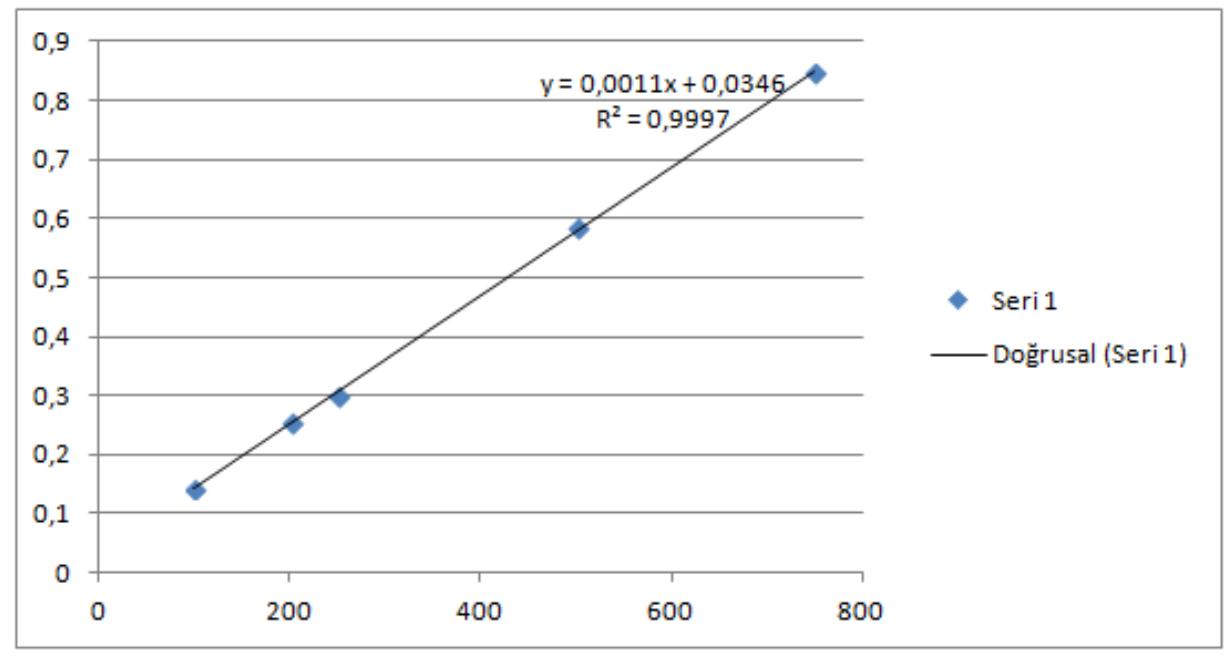

Şekil 1. Toplam fenolik madde miktarı için kullanılan gallik asit kürvesi 
Yapıs1 aydınlatılan bileşikler Tablo 1'de görüldüğü gibi terpen veya terpen benzeri, aldehidler, alkoller, esterler, asitler ve diğer bileşikler olmak üzere 6 gruba ayrıldı. Asitler $\%$ ile ana bileşen sınıfını oluşturmaktadır. Uçucu yağın ana bileșenleri ise \%35.84 palmitik asit, \%11.62 etil linoleat ve $\% 8.58$ oranında hegzahidrofarnesil asetondur.

Tablo 1. G. italicus bitkisi uçucu yağının tanımlanan kimyasal içeriği

\begin{tabular}{|c|c|c|c|c|}
\hline No & $\begin{array}{c}\text { Alikonma } \\
\text { Zamanı }\end{array}$ & Bileşiğin Adı & $\%$ Alan & Deneysel RI \\
\hline \multicolumn{5}{|c|}{ Terpen veya terpen benzeri } \\
\hline 1 & 13.095 & Limonen & 0.66 & 1031 \\
\hline 2 & 25.091 & Thimol & 0.94 & 1299 \\
\hline 3 & 27.930 & 2-Propiladamantan & 0.52 & 1366 \\
\hline 4 & 28.981 & Damaskenon & 0.52 & 1389 \\
\hline 5 & 30.219 & 2-Izobutil adamantan & 0.57 & 1418 \\
\hline 6 & 31.784 & Geranilaseton & 0.81 & 1456 \\
\hline 7 & 33.198 & $(E)-\beta$-Ionon & 0.62 & 1490 \\
\hline 8 & 36.094 & 1-sek-Butiladamantan & 0.44 & 1564 \\
\hline 9 & 37.199 & Hegzahidrofernesol & 0.62 & 1592 \\
\hline 10 & 46.416 & Hegzahidrofarnesil aseton & 8.58 & 1847 \\
\hline 11 & 46.919 & Galaksolid & 0.89 & 1861 \\
\hline 12 & 47.951 & Sklareoloksit & 0.50 & 1892 \\
\hline \multicolumn{5}{|c|}{ Aldehidler } \\
\hline 13 & 4.503 & 3-Metil pentanal & 1.56 & 728 \\
\hline 14 & 25.927 & $(E, E)$-2,4-Dekadienal & 0.54 & 1320 \\
\hline \multicolumn{5}{|c|}{ Alkoller } \\
\hline 15 & 5.146 & 3-Penten-2-ol & 1.73 & 770 \\
\hline 16 & 9.695 & 5-metil-3-heptanol & 1.26 & 943 \\
\hline 17 & 10.021 & 6-metil-2-heptanol & 0.62 & 952 \\
\hline \multicolumn{5}{|c|}{ Esterler } \\
\hline 18 & 29.208 & $p$-Metoksibenzoikasit metil ester & 1.81 & 1394 \\
\hline 19 & 47.266 & Isobutil fitalat & 1.39 & 1872 \\
\hline 20 & 51.330 & Palmitik asit etil ester & 1.20 & 1996 \\
\hline 21 & 52.256 & 13-Tetradeken-1-ol asetat & 0.95 & 2025 \\
\hline 22 & 55.933 & Etil linoleat & 11.62 & 2148 \\
\hline 23 & 56.473 & Etil oleat & 0.52 & 2164 \\
\hline \multicolumn{5}{|c|}{ Asitler } \\
\hline 24 & 43.477 & Tetradekanoik asit & 0.89 & 1762 \\
\hline 25 & 50.569 & Palmitik asit & 35.84 & 1973 \\
\hline 26 & 54.874 & 9-Oktadekenoik asit & 2.13 & 2106 \\
\hline 27 & 56.222 & Linoleik asit & 0.76 & 2155 \\
\hline 28 & 56.684 & Oleik asit & 0.53 & 2171 \\
\hline \multicolumn{5}{|c|}{ Diğer bilesikler } \\
\hline 29 & 4.29 & cis-2,5-Dimetil tetrahidro furan & 6.31 & 714 \\
\hline 30 & 4.775 & 2,4-Dimetilhegzan & 0.41 & 746 \\
\hline 31 & 40.355 & Siklotetradekan & 0.46 & 1676 \\
\hline 32 & 48.237 & Nonadekan & 0.34 & 1900 \\
\hline 33 & 54.558 & Heneikosan & 1.35 & 2101 \\
\hline \multirow[t]{2}{*}{34} & 60.376 & Trikosan & 0.86 & 2302 \\
\hline & & Toplam & 88.75 & \\
\hline
\end{tabular}


Yapılan literatür araştırmaları sonucunda $G$. atroviolaceus bitkisinin uçucu yağ kompozisyonu ile G. italicus bitkisinin uçucu yă kompozisyonu karşılaştırıldığında palmitik asit, hegzahidrofarnesil aseton, etil linoleat, limonen, (E)- $\beta$-Ionon gibi bileşiklerin ortak oldukları görülmektedir (Kahriman vd., 2012). Ancak kimyasal yapının çoğunlukla farklı olduğu tespit edilmiştir. Bu farklılıklar coğrafi konum, tür ve iklim şartlarına göre değişiklik gösterebilir.

G. italicus Miller bitkisinin uçucu yağ ekstraktlarının seçilen test bakteri ve küflerine karş1 inhibisyon seviyeleri Tablo 2'de gösterilmiştir. Antimikrobiyal çalışmada, ekstraktların konsantrasyonu arttıkça inhibisyon zonları da artmıştır. 1000 ppm ve 500 ppm' lik konsantrasyonlarda uçucu yağ ekstraktları güçlü bir antimikrobiyal aktivite göstermiştir. Uçucu yağ ekstraktı B.subtilis'e karş1 E.coli'ye daha hassas bir etki göstermiştir. Ayrıca, uçucu yağ ekstarktlarının antifungal aktivite göstermedikleri görülmüştür.
Uçucu yağ ekstraktının yüksek antioksidan aktivitesi olduğu tespit edilmiştir. G. italicus Miller'in uçucu yağ ekstraktı sarı renkli difenilpikrilhidrazin'e DPPH radikal süpürücü aktivitesi \%35.25 bulunmuştur.

Gladiolus italicus Miller'in uçucu yăg ekstraktının toplam fenolik aktivitesi 437.3 GGA/L bulunmuştur. Bitkinin yüksek fenolik madde içeriği, günlük diyette yada fonksiyonel gidalarda kullanılabileceğini göstermektedir. Tibbi bitkilerde bulunan antioksidanların güvenli ve etkili olmasının yanı sıra çeşitli biyolojik etkilere sahip olduğu da belirtilmiştir.

Türkiye florasında bulunan $G$. italicus bitkisinin antioksidan ve antimikrobiyal özelliklerinin incelendiği bu çalışma literatürdeki ilk çalışmadır. $\mathrm{Bu}$ çalışma bitkinin biyoaktif özellikleriyle ilgili daha sonraki çalışmalara katkıda bulunabilir.

Tablo 2. Gladiolus italicus Bitkisinin Uçucu Yağ Antimikrobiyal Aktivite Sonuçları

\begin{tabular}{|c|c|c|c|c|}
\hline Bakteriler & 1000 ppm & 500 ppm & 200 ppm & 100 ppm \\
\hline A. hydrophila & - & - & - & - \\
\hline B. cereus* & $6.02 \pm 0.10$ & - & - & - \\
\hline B. subtilis* & $8.10 \pm 0.10$ & - & - & - \\
\hline Ent. cloacae & - & - & - & - \\
\hline E. coli & $9.90 \pm 0.10$ & $5.18 \pm 0.10$ & - & - \\
\hline E.coli $\mathrm{O} 157: \mathrm{H} 7$ & - & - & - & - \\
\hline K. pneumoniae & - & - & - & - \\
\hline L.monocytogenes* & $10.10 \pm 0.10$ & - & - & - \\
\hline P. vulgaris & - & - & - & - \\
\hline \multicolumn{5}{|l|}{ Pseu. aeruginosa } \\
\hline Sal. typhimurium & - & - & - & - \\
\hline S. aureus* & - & - & - & - \\
\hline \multicolumn{5}{|l|}{ Maya-Küf } \\
\hline Sac. cerevisiae & - & - & - & - \\
\hline C. albicans & - & - & - & - \\
\hline A.niger & - & - & - & - \\
\hline A.flavus & - & - & - & - \\
\hline Penicillum & - & - & - & - \\
\hline
\end{tabular}

* Çalışmada kullanılan gram pozitif bakterileri belirtmektedir. 


\section{Teşekkür}

Bu çalışma, Gümüşhane Üniversitesi Bilimsel Araştırma Projeleri (GÜBAP) birimi tarafindan 13.F5115.02.2 nolu proje kapsamında desteklenmiştir. Bitki teşhisini yapan Dr. Mutlu GÜLTEPE'ye teşekkürlerimizi sunarı.

\section{Kaynaklar}

Fazly Bazzaz, B. S., Haririzadeh, G., Imami, S.A. ve Rashed, M.H., 1997. Survey of Iranian Plants for Alkaloids, Flavonoids, Saponins, and Tannins [Khorasan Province], International Journal of Pharmacognosy, 35, 17-30.

Gámez-Meza, N., Noriega-Rodríguez, J. A., Medina-Juárez, L.A., Ortega-García J., Cázarez-Casanova $R$. ve AnguloGuerrero O., 1999. Antioxidant activity in soybean oil of extracts from thompson grape bagasse, Journal of the American Oil Chemists' Society, 76, 1445-1447.

Goldblatt, P., 1996, Gladiolus in Tropical Africa, Systematics Biology \& Evolution. Portland, OR, USA: Timber Press, 7-9p.

Hajiboland, R. ve Manafi, M. H. 2007. Flora of heavy metal-rich soils in NW Iran and some potential hyperaccumulator and accumulation species, Acta Botanica. Croatica, 66, 177-195.

Kahriman, N., Yücel, M., Yaylı, B., Aslan, T., Karaoğlu, S. A. ve Yaylı, N., 2012. Chemical Composition and Antimicrobial Activity of the Volatile of Gladiolus atroviolaceus Boiss., Asian J. Chem., 24, 1461-1464.

Kahriman, N., Albay, C. G., Dogan, N., A. Usta, Karaoğlu, S. A. ve Yaylı, N., 2010. Volatile Constituents and Antimicrobial Activities from Flower and Fruit of Arbutus unedo L., Asian J. Chem., 22, 6437-6442.
Maksimovic, Z.A., Dordeviv, S. Ve Mraovic, M., 2005. Antimicrobial Activity of Chenopodium botrys Essential Oil, Fitoterapia,76: 112-114.

Manning, J., ve Goldblatt. P., 2008, The Iris Family: Natural History and Classification. Portland, Oregon: Timber Press, 138-142p.

Nguedia, J. C. A., Etoa, F. X., Benga, V. P., Lontsi, D., Kuete, Y. ve Moyou R. S., 2004. Anti-candidal property and acute toxicity of Gladiolus gregasius Baker (Iridaceae), Pharm. Méd. Trad. Afr., 13, 149-159.

Öztürk, M. ve Özçelik, H., 1991. Useful plants of East Anatolia. SISKAV (Siirt İlim, Spor, Kültür ve Araştırma Vakfi), 196 p.

Perez, C., Pauli, M. ve Bazerque, P., 1990. An Antimicrobial Assay by the Agar Well Diffusion Method, Acta Biologae et Medicine Experimentalis, 15, 113115.

Sağdıç, O. ve Özcan, M., 2003. Antibacterial Activity of Turkish Spice Hydrosols, Food Control, vol.14, 141-143.

Sağıroğlu, M., ve Akgül, G., 2014. Gladiolus osmaniyensis (Iridaceae), a new species from South Anatolia, Turkey. Turkish Journal of Botany, 38: 31-36.

Sanchez-Moreno, C., Larrauri, J. A. ve SauraCalixto, F., 1998. A Procedure to Measure the Antiradical Efficiency of Polyphenols, Journal of the Science of Food and Agriculture, 76, 270-276.

Skaltsa, H. D., Demetzos, C. Lazari, D. ve Sokovic, M. 2003. Essential oil analysis and antimicrobial activity of eight Stachys species from Greece, Phytochemistry, 64, 743.

Tan, K., ve Edmondson, J. R., 1984. Gladiolus L. In: Davis, PH, editor. Flora of Turkey and the East Aegean 
Islands, Vol. 8. Edinburgh: Edinburgh University Press, 441-450p.

Tan, K., Mathew, B., ve Baytop, A., 2006. Gladiolus attilae (Iridaceae), A new species from East Anatolia, Turkey. Phytol Balcan 12: 71-73p.

Tunalıer, Z., Kırımer, N. ve Başer, K.H.C., 2002. The composition of essential oils from various parts of Juniperus foetidissima, Chem. Nat. Comp., 38, 43-47.
Üçüncü, O., Yaylı, N., Volga, C., Yaylı, N. ve Terzioğlu, S. 2009. Chemical Composition of the Essential Oils from the Flower, Leaf and Stem of Aquilegia olympica Grown in Turkey, Asian J. Chem., 21, 6569.

Wang, D. Y., Ye, Q., Li, B. G. ve Zhang, G. L. 2003. A New Anthraquinone from Gladiolus gandavensis, Natural Product Research, 17, 365-368. 